and $\$ 125$ by political parties. The boycott of the Hamas government has led to most of this aid being blocked.

Surprisingly, some key health indicators are good. Infant mortality is close to $30 / 1000$, almost all children are fully vaccinated, and the proportion of professionally assisted deliveries is high. But the limits of these technology based interventions in isolation are becoming clear. We see a disturbing pattern of excess death rates, especially for young men. Non-communicable diseases and cancer are growing in importance. ${ }^{1}$ Prevention requires interventions to change behaviour (such as diet and smoking control). Such change is not readily accomplished without strong government control, which seems increasingly remote.

\section{Where next?}

One reason for the current situation is the international community's focus on the palliative effect of aid rather than promotion of human security and human development concerns. It is time to move beyond the narrow technical and medical approaches to health and for the region to exert independent control over its health issues. One way ahead is to adopt a population based approach that concentrates on equity and the social, political, and economic determinants of health. For years, the world has been impressed by the remarkable outcomes of public health and education programmes in the Palestinian refugee community. Yet, these outcomes are not sustainable and cannot subvert the requirements for a stable and open society, such as equity of access to quality services, planning for development, productive employment, free movement of people and goods, and democratic governance.

Competing interests: None declared.

1 Humanitarian Policy and Conflict Research. Population projections for socioeconomic development in the Gaza Strip. Boston, MA: Harvard University Press, 2006.

UN Office for the Coordination of Humanitarian Affairs. Gaza Strip situ ation report. www.humanitarianinfo.org/opt (accessed 3 Oct 2006).

Keating, M, Le More A, Lowe R. Aid, diplomacy and facts on the ground. London: Chatham House, 2005.

doi 10.1136/bmj.38993.390822.68

\title{
Darfur-dependent population at risk of another catastrophe
}

Remco van de Pas

\section{Prinses \\ Margrietstraat 8, $5056 \mathrm{HL}$ Berkel-Enschot, \\ Netherlands \\ Remco van de Pas physician}

R.vandepas@gmx.net

BMJ 2006;333:846-7
When I arrived in south Darfur in late 2005, the humanitarian situation, although fragile, seemed under control. The estimated 100000 internally displaced people at Kalma camp, where I worked in a primary health clinic, had stable health indicators. My colleagues and I worked hard on training local health workers and building infrastructure within the community. The first months of 2006 were hopeful, but six months later the situation has changed dramatically.

Since February 2006, displacement has increased in all states of Darfur. New internal refugees arrive daily in the camps on the edge of Nyala. These camps have few facilities available, and violence and sexual abuse are rampant.

The World Health Organization and United Nations agencies have medical professionals trained in managing outbreaks of disease and coordinated approaches to complex emergencies. Unfortunately, many of these trained professionals have already left Darfur as a result of the insecurity and reduced funds available for non-governmental organisations in the region. WHO has introduced incentives to hospital staff and compensates hospitals for operating expenses by providing essential medicines. Although this strategy is a valid response to the initial crisis, it becomes counterproductive in the long term. Health workers and the local community become dependent on this aid without creating a viable health system.

\section{Humanitarian aid}

International non-governmental organisations share responsibility with WHO for this flawed situation. In 2004, they flocked to confront an emergency situation,

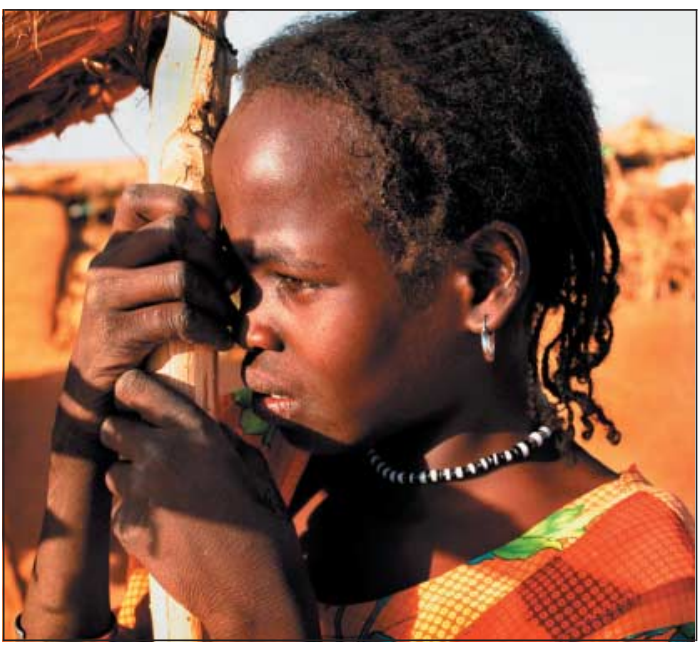

People in Darfur lack food and medicines

as this was the place where substantial funds could be obtained. In the health sector, ambitious programmes were set up hastily and focused on accessible camps for displaced people rather than on isolated or insecure areas that were difficult to reach. ${ }^{1}$ This led to an imbalance in available services. In some places two organisations provided the same essential non-food items, such as blankets and bed nets, and some camps had three health clinics whereas others had none. Kalma camp has become politicised and violent partly as a result of this dynamic.

Humanitarian access is currently hampered by an escalation of violence. Twelve humanitarian workers were killed in July and August 2006. Access is at its lowest since the beginning of the conflict in 2003 . 


\section{Humanitarian indicators for Darfur} (www.reliefweb.int)

Population dependent on humanitarian aid: 3 million Number of internally displaced people: 1.9 million Cumulative excess mortality: 130000400000 deaths $^{3}$ Crude mortality: 2.6/10 000/day (2004) <1.0/ $10.000 /$ day (2005)

Maternal mortality: 590 deaths/100 000 live births Women's lifetime risk of dying from pregnancy related causes: 1 in 30

Forty per cent of the affected population in north Darfur is not receiving health care, and 370000 people across Darfur did not receive monthly rations in July. ${ }^{2}$

One of the most important lessons is that without durable peace, the health gains can easily be lost. Health indicators must be used as an advocacy tool in the political process. The international community must critically examine its efforts in order to achieve sustainable results. Non-governmental organisations must start small scale programmes, as these can be managed over a prolonged time, even with reduced funds or fewer health professionals. Darfur is on the edge of yet another humanitarian catastrophe. We are obliged to prevent it.

Competing interests: None declared.

1 UN Office for Coordination of Human Affairs. Sudan: NGOs/UN coverage per locality in Southern Darfur (as of 11 Jun 2006). www.reliefweb.int/rw/ per locality in Southern Darfur (as of 11 Jun 2006). www.reliefweb.int/rw/
RWB.NSF/db900SID/LPAA-6QTPB4?OpenDocument\&rc = 1\&emid = RWB.NSF/db900SID/LPAA-6QTPB4?
ACOS-635PJQ (accessed 5 Oct 2006).

2 UN Office for Coordination of Human Affairs. Sudan: Briefing by Jan Egeland, under-secretary-general for humanitarian affairs and emergency relief coordinator, on the humanitarian situation in Darfur, 29 Aug 2006. www. reliefweb.int/rw/rwb.nsf/db900SID/KKEE-6T4QX5?OpenDocument\& emid $=$ ACOS-635PJQ\&rc $=1$ (accessed 5 Oct 2006).

3 Petersen AH, Tullin L. The scorched earth of Darfur: patterns in death and destruction reported by the people of Darfur, January 2001-September 2005. Copenhagen: Bloodhound, 2006.

doi $10.1136 /$ bmj. 38986.426354 .68

\title{
Iraq lacks facilities and expertise in emergency medicine
}

\author{
Bassim Irheim Mohammed Al Sheibani, Najah R Hadi, Tariq Hasoon
}

Iraq has a population of over 26 million and more than 180 hospitals, but only a handful have emergency departments. As the violence escalates, and we attempt daily to deal with the devastating effect of multiple deaths and severe injury, the reality is that we cannot provide any treatment for many of the victims. Emergency medicine in Iraq has never developed to meet such unprecedented demand. Emergency departments are staffed by doctors who do not have the proper experience or skills to manage emergency cases.

Official figures from Iraqi authorities and UN agencies suggest that more than 14338 Iraqi civilians were killed between January and June $2006 .{ }^{1}$ Additionally, the report indicated that the killing of civilians is rising since there were more than 5800 deaths and over 5700 people injured during May and June 2006. Medical staff working in emergency departments admit that more than half of those killed could have been saved if trained and experienced staff were available.

Lack of expertise is aggravated by the lack of medical equipment, supplies, and drugs. Many emergency departments are no more than halls with beds, fluid suckers, and oxygen bottles. Radiography facilities, sonar machines, and laboratory services are unattainable luxuries.

Ambulances are sent to pick up casualties with just the drivers, who have no paramedical training. Injured people are usually escorted by family members, who obviously do not know how to use any of the available medical equipment. If the person is lucky enough to arrive at a hospital alive, staff insert an intravenous cannula and send him or her on to one of the few specialised centres.

\section{We need international support}

Doctors face challenges beyond poor resources and lack of emergency. Perceived as members of an elite, they have become the target of daily insurgent activities. Many have been killed, others have fled the country, and those who decided to stay have closed their private clinics, fearing for their lives. Last week a close colleague of mine was killed as he left his clinic; three masked people stopped and fired six bullets into his head, chest, and abdomen. Who are these people and why did they kill him? We do not know. The ministry of health has held at least two national conferences this year to discuss what should be done to save the lives of doctors.

In Diwaniyah College of Medicine, we are trying to establish a unit specialised in emergency medicine to train the medical students and doctors. The project is still in its infancy because it needs support from the international medical community. We were offered a training course by a colleague in Turkey but we could not take it up. The travel costs alone were equivalent to two years of a doctor's salary. International Medical Corp-Iraq also offered a training course but it has not been forthcoming.

Iraqi doctors are doing their best in difficult circumstances. Our experience has taught us that poor emergency medicine services are more disastrous than the disaster itself. But despite the daily violence that is crushing Iraq, the international medical community is doing little more than looking on.

Competing interests: None declared.

1 Centre for Excellence in Disaster Management and Humanitarian Assistance. Iraq humanitarian assistance report: overview. www.coe-dmha.org/ HARIraq.cfm (accessed 20 Jul 2006).

doi $10.1136 /$ bmj.38986.476782.68
Diwaniyah College

of Medicine,

PO Box 279,

Diwaniyah, Iraq

Bassim Irheim

Mohammed Al

Sheibani

lecturer physician

Kufa College of

Medicine, Iraq

Najah R Hadi

professor

International

Medical Corps, Iraq

Tariq Hasoon

senior health

development

programme officer

Correspondence to:

B I M Al Sheibani

jumabassim@

yahoo.co.uk

BMJ 2006;333:847 